\title{
A high performance liquid chromatography method for determination of furfural in crude palm oil.
}

\begin{abstract}
A modified steam distillation method was developed to extract furfural from crude palm oil (CPO). The collected distillates were analysed using high performance liquid chromatography (HPLC) coupled with an ultraviolet diode detector at $284 \mathrm{~nm}$. The HPLC method allowed identification and quantification of furfural in CPO. The unique thermal extraction of CPO whereby the fresh fruit bunches (FFB) are first subjected to steam treatment, distinguishes itself from other solvent-extracted or cold-pressed vegetable oils. The presence of furfural was also determined in the fresh palm oil from FFB (without undergoing the normal extraction process), palm olein, palm stearin, olive oil, coconut oil, sunflower oil, soya oil and corn oil. The chromatograms of the extracts were compared to that of standard furfural. Furfural was only detected in CPO. The CPO consignments obtained from four mills were shown to contain 7.54 to $20.60 \mathrm{mg} / \mathrm{kg}$ furfural.
\end{abstract}

Keyword: Carbohydrate; Crude palm oil; Furfural; Hemicelluloses; HPLC. 